\title{
Cigarette smoke inhalation and the acute airway response
}

\author{
TIM HIGENBOTTAM, COLIN FEYERABAND, AND T J H CLARK
}

From Guy's Hospital, London

ABSTRACT The acute airway response to smoking varying numbers (one to four) of identicati cigarettes in rapid succession and smoking single cigarettes of differing tar/nicotine yields wa志 assessed repeatedly in 13 healthy smokers. The airway response was variable, indicating airwa䓂 narrowing consistently in only three subjects. There appeared no difference between force $\Phi$ spirometry and measurement of airway resistance in detecting the airway response. No relationship was observed between the airway response and amount of smoke inhaled into the lungs as measure either by changes in venous blood nicotine or percentage carboxyhaemoglobin. When five smokers. inhaled smoke directly from a cigarette acute airway narrowing was consistently observed. A normat? smoking pattern consisting of an initial drag of smoke into the mouth, followed after a pause bo inhalation of smoke diluted with air, did not consistently cause airway narrowing although similag amounts of smoke as the direct drag were inhaled as assessed by changes in venous blood nicotines The manner of smoke inhalation affects the relative concentrations of the different constituents of smoke reaching the lungs and also appears to be the main determinant of the acute airway response्ष to smoking, which was unrelated to the number of cigarettes smoked or the tar content of the smoke? This suggests that patterns of smoke inhalation may influence the pathogenesis of bronchial disease्ट associated with smoking.

Despite a well-advertised association with carcinoma of the lung and chronic obstructive bronchitis, cigarette smoking remains a remarkably common habit, and this is even more surprising as the habit involves inhalation of smoke into the lungs. ${ }^{1}$ Cigarette smoke, when inhaled, behaves in a similar way to other irritant gases, vapours, and dusts, in causing acute dyspnoea, coughing, and acute airway narrowing. ${ }^{2} 3$ These responses probably represent vagally mediated protective reflexes as they promote proximal deposition of smoke particles and their subsequent ejection from the lungs by coughing and mucociliary clearance. ${ }^{45}$ However, when large numbers of smokers have been studied only a minority appear to develop any of these responses and only a few develop acute airway narrowing after smoking a single cigarette. ${ }^{6}$ 7

The question as to how the majority of smokers avoid an acute airway response to inhaled cigarette smoke has not been answered and is important as it suggests two conflicting theories

Address for reprint requests: Dr T Higenbottam, Guy's Hospital, St Thomas Street, London SE1 9RT. concerning the relation between the acute res sponse and the development of chronic obstructive bronchitis in a minority of smokers. It could be argued that the absence of an acute protective airway response enables airways to be chronically exposed to those constituents of cigarette smoke which promote chronic intrinsic airway disease Alternatively, those individual smokers exhibiting an acute cigarette-induced response may represen a susceptible population who through repeated. provocation proceed to develop chronic obstruc N tive bronchitis. ${ }^{8}$

Previous work on the subject has suffered from difficulties with measurement of the amount of smoke inhaled so that differences in inhaled dose may account for the previously reported variatiofe in acute response. ${ }^{6}$ Furthermore, cigarettes have undergone a progressive reduction in tar and nicotine yield over the last few years ${ }^{1}$ which makes interpretation of earlier results difficult asp most modern cigarettes yield a potentially less irritant smoke.

We have attempted to identify those factors? which may be considered important in determin 8 ing the acute airway response to cigarette smoke 
and by using changes in venous blood nicotine or carboxyhaemoglobin we have estimated the amount of smoke inhaled. By varying the number of identical cigarettes smoked in a rapid succession and varying the tar/nicotine yield of cigarettes we have attempted to identify whether quantity or type of cigarette smoke are also important determinants. Finally, the effects of differing patterns of smoke inhalation have been compared in order to decide whether the way in which smoke is inhaled, rather than quantity or type of smoke, influences the acute airway response.

\section{Methods}

Five separate experiments were undertaken. From a group of 13 asymptomatic male smokers, individuals were selected to take part in each (table 1). Each subject had a normal $\mathrm{FEV}_{1}$ and their mean age was 27 years.

\section{ONE TO FOUR CIGARETTES}

In experiments 1 and 2 an assessment was made of the acute airway response to smoking differing numbers of a low to middle tar filtered cigarette (table 2) in rapid succession. Each of four subjects smoked on four separate days one to four cigarettes, the order being randomised by means of a $4 \times 4$ latin square experimental design. ${ }^{9}$ Airway response to smoking in experiment 1 was determined by forced spirometry, using a dry spirometer on-line to a minicomputer providing 12 variables from an analysis of maximal expir-

Table 1 The separate experiments (1-5) showing the type of study, the measurement used, and which subjects took part

\begin{tabular}{|c|c|c|c|c|c|}
\hline \multirow[b]{2}{*}{$\begin{array}{l}\text { Method of } \\
\text { assessment }\end{array}$} & \multicolumn{2}{|c|}{$\begin{array}{l}\text { Varying numbers } \\
\text { of cigarette } \\
\text { measurements }\end{array}$} & \multicolumn{2}{|c|}{$\begin{array}{l}\text { Varying types } \\
\text { of cigarette } \\
\text { measurements }\end{array}$} & \multirow{2}{*}{$\begin{array}{l}\text { Varying patterns } \\
\text { of smoking } \\
\text { measurements } \\
\text { Airway } \\
\text { resistance }\end{array}$} \\
\hline & $M E F V C$ & $\begin{array}{l}\text { Airway } \\
\text { resistance }\end{array}$ & $M E F V C$ & $\begin{array}{l}\text { Airway } \\
\text { resistance }\end{array}$ & \\
\hline $\begin{array}{l}\text { Experiment } \\
\text { number }\end{array}$ & $I$ & 2 & 3 & 4 & 5 \\
\hline \multicolumn{6}{|l|}{ Subject } \\
\hline 1 & - & + & - & - & - \\
\hline 2 & + & + & - & - & - \\
\hline 3 & - & + & - & - & - \\
\hline 4 & - & + & - & - & - \\
\hline 5 & + & - & - & - & - \\
\hline 6 & + & - & - & - & - \\
\hline 7 & + & - & - & - & - \\
\hline 8 & - & - & + & - & - \\
\hline 9 & - & - & + & + & + \\
\hline 10 & - & - & + & + & + \\
\hline 11 & - & - & + & + & + \\
\hline 12 & - & - & + & + & + \\
\hline 13 & - & - & - & + & + \\
\hline
\end{tabular}

atory flow volume curves (MEFVC) (table 3). Using the same experimental design inspiratory airway resistance and associated lung volume measured in a constant volume whole body plethysmography were used to assess acute airway narrowing in experiment 2.

\section{FIVE CIGARETTE TYPES}

Experiments 3 and 4 each involved five subjects (table 1), smoking on separate days a single rigarette selected from one of five types (table 2 ) of differing tar/nicotine yields. One of these cigarettes contained $30 \%$ of a non-tobacco substitute (NSM) and one was a full strength unfiltered cigarette. The order by which each subject smoked each type of cigarette was randomised using a $5 \times 5$ latin square design. Airway response to smoking was measured in experiment 3 with MEFVC analysis and airway resistance was used in experiment 4.

\section{PATTERNS OF INHALATION}

In experiment 5 five subjects smoked a single cigarette of low to middle tar category (table 2) in three different ways on separate days (table 1): (1) drawing smoke into their mouths but not inhaling (mouth smoking); (2) drawing smoke directly from the cigarette into their lungs; (3) smoking normally. The airway response was determined with airway resistance measurements and the order of different smoking patterns was randomised. Breathing patterns during this study were also monitored with a single pair of magnetometer coils across the anteroposterior diameter

Table 2 The different types of cigarette

\begin{tabular}{llll}
\hline Tar category & Plain/filtered & Nicotine yield $\begin{array}{l}\text { Carbon monoxide } \\
\text { yield }\end{array}$ \\
\hline Low tar $(30 \% \mathrm{NSM})$ & Filtered & $0.70 \mathrm{mg} / \mathrm{cig}$ & $11.0 \mathrm{mg} / \mathrm{cig}$ \\
Low tar & Filtered & $1.01 \mathrm{mg} / \mathrm{cig}$ & $12.1 \mathrm{mg} / \mathrm{cig}$ \\
Low to middle tar & Filtered & $1.36 \mathrm{mg} / \mathrm{cig}$ & $19.3 \mathrm{mg} / \mathrm{cig}$ \\
Middle to high tar & Plain & $1.86 \mathrm{mg} / \mathrm{cig}$ & $15.0 \mathrm{mg} / \mathrm{cig}$ \\
High tar & Plain & $3.39 \mathrm{mg} / \mathrm{cig}$ & $18.2 \mathrm{mg} / \mathrm{cig}$ \\
\hline
\end{tabular}

Table 3 Measurements from the maximal expiratory flow volume curves

Vital capacity

Forced expired volume in one second

Forced expired ratio

Forced expired flow rate

Expiratory flow at $75 \%$ vital capacity

Expiratory flow at $60 \%$ vital capacity

Expiratory flow at $50 \%$ vital capacity

Expiratory flow at $25 \%$ vital capacity

Mean flow between $70-25 \%$ vital capacity

Mean flow between $60-20 \%$ vital capacity

Time to no flow

Time to peak flow 
of the ribcage at the level of the xiphisternum, ${ }^{10}$ being calibrated for volume measurement before the experiment began. By observing the glow of the burning cone of the cigarette as each drag of smoke was taken, the duration and timing of each drag was recorded in relation to the breathing pattern on a multichannel recorder.

DOSE OF SMOKE INHALED

The amount of smoke inhaled while smoking, was measured in experiments 1,2 , and 5 by determining changes in level of venous blood nicotine from samples taken before and two minutes after completing the last cigarette. ${ }^{11}$ In experiments 3 and 4 change in venous carboxyhaemoglobin level was determined spectrophotometrically. ${ }^{12}$ We considered that this would provide a more reliable assessment of smoke inhalation, as carbon monoxide deliveries on the different cigarettes were more comparable than their nicotine yields (table 2).

\section{STATISTICAL ANALYSIS}

In each experiment six measurements (either MEFVC or airway resistance) were performed in rapid succession by every subject before each smoking session and repeated within two minutes of completing the test cigarettes. Factorial analysis of variance was used to assess the results in each experiment. By using the $F$ ratios, the significance of the main factors could be determined $^{9}$ - for example, variation caused by different subjects, order of each treatment, or effects of smoking were compared with the background or residual variation found from the variation within the groups of six replicated measurements. We were also able in a similar way to determine the significance of interaction between these factors; for example, to decide if all subjects reacted in the same way to smoking, the variation attributable to the interaction between the factors, subjects, and treatments being compared with the residual variation to provide an $F$ ratio.

In all five experiments each variable used to assess the airway response was analysed separately. This amounted to 12 variables derived from the MEFVC (table 3). In the body box studies, in addition to airway resistance (Raw) and the associated lung volume (Vtg), the variables airway conductance and specific airway conductance (sGaw) together with its logarithmic transformation were also calculated. Specific airway resistance (sRaw) and a covariance correction of airway resistance with lung volume as the covariate were determined as well. ${ }^{13}$ Each of these six variabless was also analysed separately. Although many ofo these variables measured in either the MEFVCo and body box are not independent of one another, $\overline{ }$ the risks of a falsely positive result are greatlyo enhanced by the large number of variables beinge examined. For example, in the MEFVC study where 12 variables are under study the chances of finding such a significant result by accident $\vec{\omega}$ may well exceed $80 \%$. To avoid this type of statis-o tical error and to provide the equivalent of a $p_{\vec{x}}$ value of 0.05 for each variable, the overall $p$ valuew for each experiment when testing the $F$ ratios for significance was 0.0043 and 0.0073 foriv the MEFVC studies and body box studies respectively. ${ }^{14}$

When determining the size of change in eachvariable after smoking, the differences between mean values of each variable before and after smoking were contrasted with a $95 \%$ confidence $\vec{\bullet}$ interval derived from the standard error using ao multiple comparison test of Dunn. ${ }^{14}$ Such $a_{0}$ method was applied once more to reduce theo risks of statistical error as many comparisons of means were being performed; for example in experiments 3 and 4,25 pairs of means were? compared.

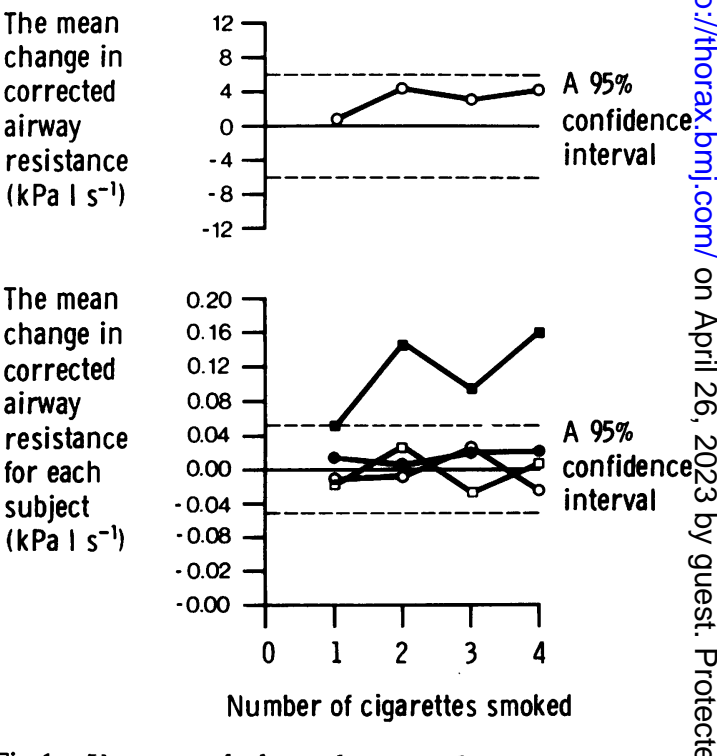

Fig 1 Upper graph shows the mean change in covariance corrected airway resistance for all subjects. Lower graph $\sigma$ shows the changes in each individual related to cigarette consumption and the symbols represent each subject: subject $1 \square$, subject $2 \bigcirc$, subject $3 \bigcirc$, subject $4 \square$. 


\section{Results}

EXPERIMENTS 1 AND 2

\section{Airway resistance}

There was no increase in airway resistance after smoking any of the number of cigarettes when the mean results for all four subjects were considered (fig 1). However, the subjects behaved differently after smoking, the interaction between subjects and treatments being significant for the variables $R a w, \log s G a w$ and $s R a w$ ( $p$ values less than 0.0073 ). Viewing the changes in airways resistance after smoking against the $95 \%$ confidence interval it will be seen that subject 1 showed airway narrowing after one, two, three and four cigarettes (fig 1), whereas no change in airways resistance occurred with the other subjects no matter how many cigarettes they had smoked.

\section{Maximal expiratory flow volume curves}

When using the MEFVC analysis to detect airway narrowing, no overall change occurred after smoking, taking all four subjects as a group (fig 2 for PEFR). Individual smokers again showed differing responses particularly for PEFR and FEV ( $p$ values less than 0.0043 ) with only subject 6 showing evidence of reduction of PEFR and then
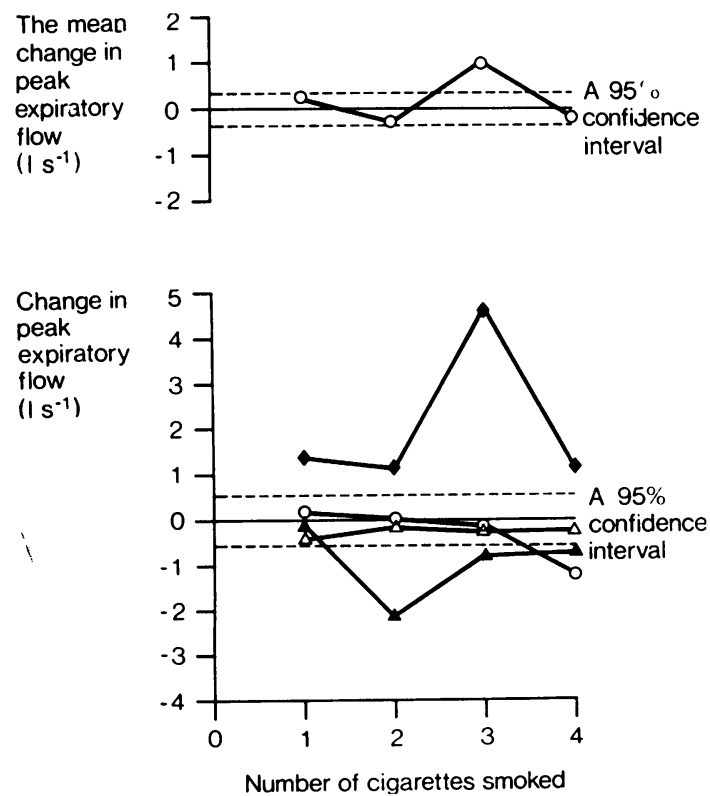

Fig 2 Upper graph shows the mean change in PEFR for all four subjects after smoking each number of cigarettes. Lower graph shows individual reductions in PEFR: subject $2 \bigcirc$, subject $5 \triangle$, subject $6 \Delta$, subject 7 only after two, three, and four cigarettes had been smoked in succession (fig 2).

\section{Change in level of nicotine}

Although there was a general tendency for more smoke to be inhaled with increasing numbers of cigarettes smoked (fig 3) subjects 1 and 6 did not appear to inhale more smoke than the other subjects, nor was there any apparent relationship between the change in venous blood nicotine and change in Raw or PEFR.

\section{EXPERIMENTS 3 AND 4}

\section{Airway resistance}

Only for the high tar cigarettes was there a mean increase in airway resistance for all five subjects (fig 4). However, most of this was contributed by one individual, subject 10 , and he with subject 12 were the only ones to show evidence of acute airway narrowing after smoking (fig 4). For the remaining subjects there was no change in Raw after smoking. There was no relationship between the tar yields of the cigarettes and the increase in airway resistance in any of the subjects.

\section{Maximal expiratory flow volume curves}

The subjects reacted differently to smoking. There was a trend of a greater reduction in PEFR with higher tar cigarettes but for the variables. PEFR and mean flow rates between $75-25 \%$ and $60-20 \%$

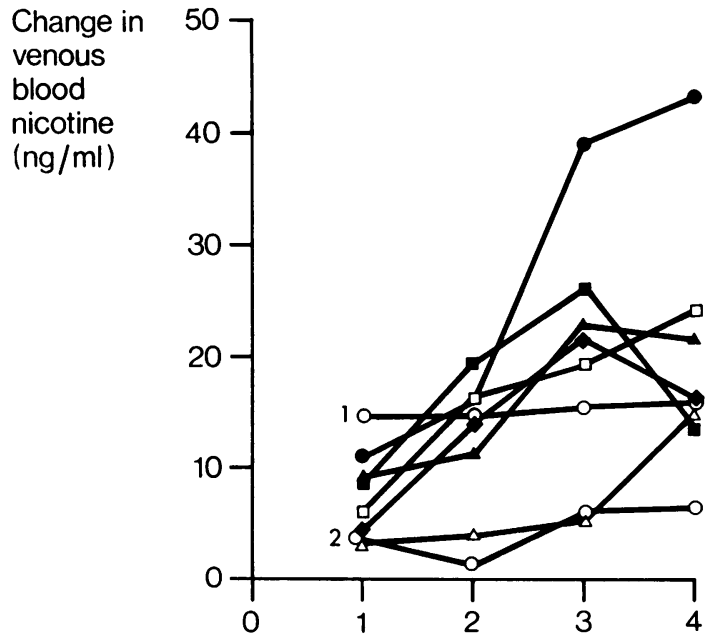

Number of cigarettes smoked

Fig 3 Changes in venous blood nicotine related to cigarette consumption for both the body box and MEFVC study in seven subjects. Subject $I \square$, subject $2 \bigcirc$ (one body box and two MEFVC measurements), subject $3 \bigcirc$, subject $4 \square$, subject $5 \triangle$, subject $6 \Delta$, subject 7 
The mean change in corrected airway resistance $\left(\mathrm{KPa} \mid \mathrm{s}^{-1}\right)$

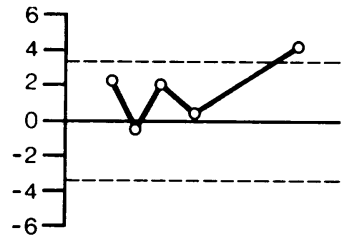

A $95 \%$ confidence interval

Change in
corrected
airway
resistance $\left(\mathrm{kPa} \mid \mathrm{s}^{-1}\right)$

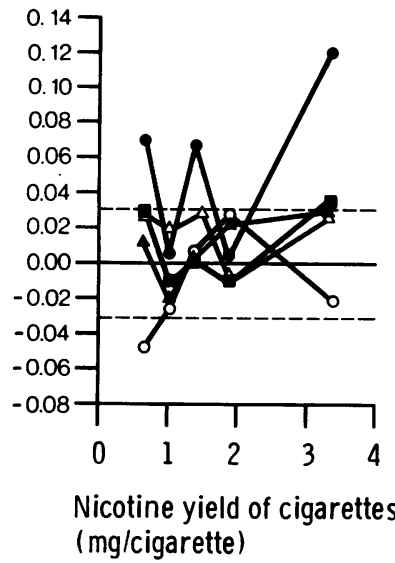

Fig 4 Mean change in covariance corrected airway resistance for all subjects is shown on the upper graph, and changes for each individual against nicotine yield of cigarettes smoked on the lower graph. Subject $9 \bigcirc$, subject $10 \bigcirc$, subject $11 \triangle$, subject $12 \square$, subject $13 \Delta$.

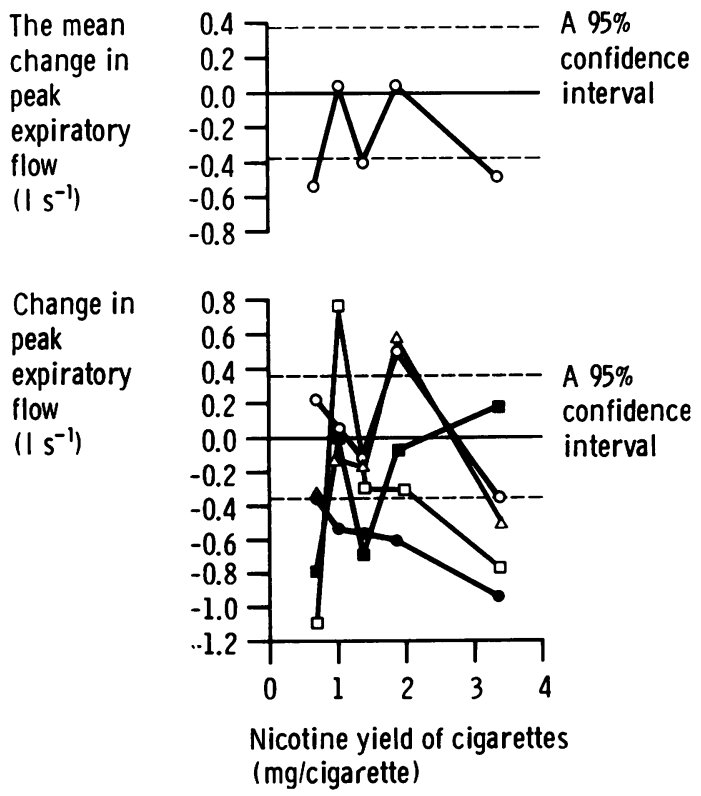

Fig 5 Mean change in PEFR in all subjects is shown on the upper graph, and individual results on the lower. Subject $8 \square$, subject 90 , subject $10 \bigcirc$, subject $11 \triangle$, subject 12 . of vital capacity there was significant interaction between treatments and subjects ( $p$ value les? than 0.0043). This can be seen in fig 5 where $\overline{\bar{\sigma}}$ subject 11 showed a reduction in PEFR on one occasion, subjects 8 and 12 on two occasions, and® subject 10 reacted to all five cigarettes. Tar yield of the cigarettes did not appear to be related $\rightarrow$ to the degree of reduction in PEFR except in subject 10 .

Change in level of carboxyhaemoglobin

The subjects who had shown acute airway nar-cis rowing did not appear to have inhaled more cigarette smoke as measured by change in car-in boxyhaemoglobin than the non-responders noro was there any relationship between the degree of $\frac{}{5}$ airway narrowing and amount of smoke inhaled.-

EXPERIMENT 5

Patterns of smoke inhalation

The "normal" pattern of smoking in each of the" five subjects appeared to consist of two stages. The first stage was a "mouth" phase when smoke

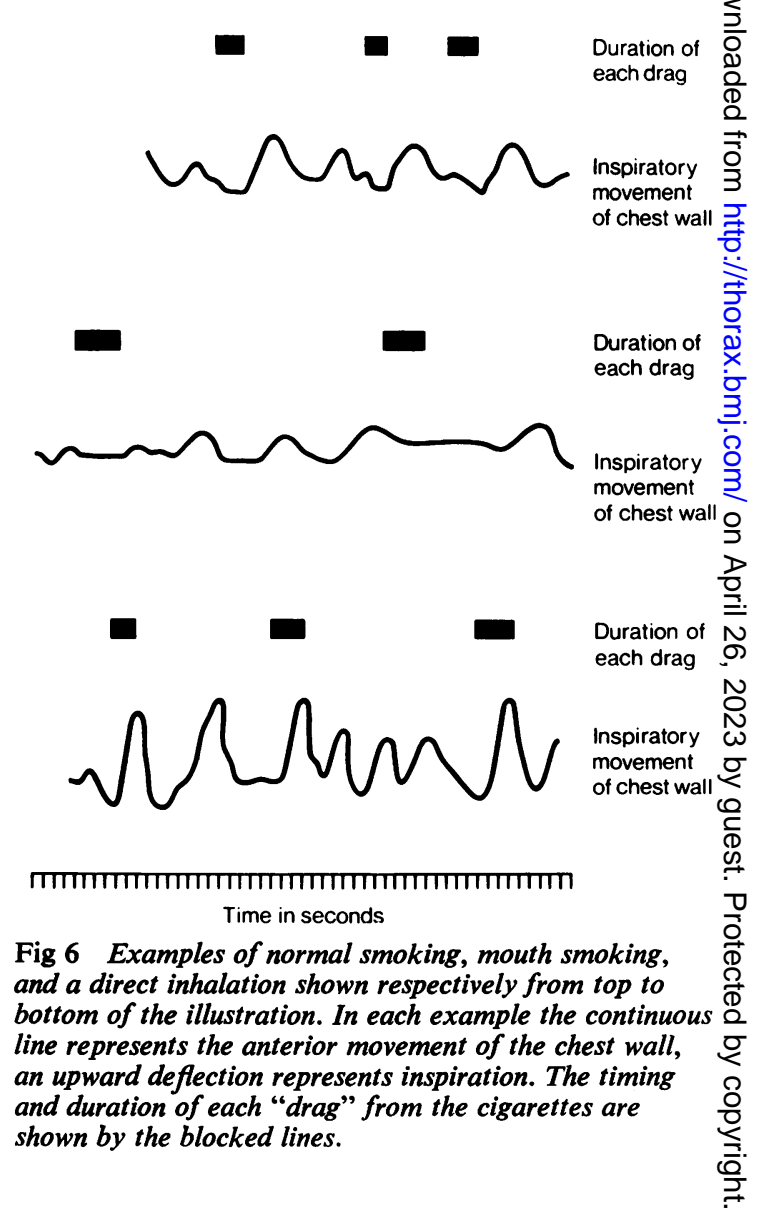


Table 4 Mean volumes (with standard errors) of inhaled smoke obtained from the measurement of the anterior chest wall for the differing patterns of smoking. The change in venous blood nicotine is also recorded together with number of drags of smoke

\begin{tabular}{|c|c|c|c|c|c|c|c|c|c|}
\hline \multirow[t]{3}{*}{ Subject } & \multicolumn{9}{|c|}{ Pattern of smoking } \\
\hline & \multicolumn{3}{|l|}{ Mouth } & \multicolumn{3}{|l|}{ Normal } & \multicolumn{3}{|c|}{ Direct inhalation } \\
\hline & $\begin{array}{l}\text { Mean } \\
\text { inhaled volume } \\
m l( \pm S E)\end{array}$ & $\begin{array}{l}\text { Number } \\
\text { of puffs }\end{array}$ & $\begin{array}{l}\text { Change in } \\
\text { nicotine } \\
\text { ng/ml }\end{array}$ & $\begin{array}{l}\text { Mean } \\
\text { inhaled volume } \\
m l( \pm S E)\end{array}$ & $\begin{array}{l}\text { Number } \\
\text { of puffs }\end{array}$ & $\begin{array}{l}\text { Change in } \\
\text { nicotine } \\
\text { ng/ml }\end{array}$ & $\begin{array}{l}\text { Mean } \\
\text { inhaled volume } \\
m l( \pm S E)\end{array}$ & $\begin{array}{l}\text { Number } \\
\text { of puffs }\end{array}$ & $\begin{array}{l}\text { Change in } \\
\text { nicotine } \\
\text { ng/ml }\end{array}$ \\
\hline 9 & 0 & 11 & $-1 \cdot 5$ & $96( \pm 42)$ & 13 & $9 \cdot 3$ & $54( \pm 35)$ & 7 & $15 \cdot 2$ \\
\hline 10 & 0 & 5 & $-0 \cdot 1$ & $34( \pm 18)$ & 11 & $13 \cdot 5$ & 0 & 5 & 0.6 \\
\hline 11 & 0 & 19 & -0.3 & $151( \pm 37)$ & 19 & $20 \cdot 5$ & $5( \pm 1)$ & 6 & 1.89 \\
\hline 12 & 0 & 7 & $-1 \cdot 0$ & $116( \pm 32)$ & 8 & 19.0 & $134( \pm 17)$ & 4 & $15 \cdot 4$ \\
\hline 13 & 0 & 14 & $-1 \cdot 1$ & $152( \pm 16)$ & 20 & $20 \cdot 5$ & $160( \pm 28)$ & 6 & $12 \cdot 0$ \\
\hline
\end{tabular}

was drawn into the mouth without any evidence of inhalation, the anterior chest wall remaining stationary. The second stage began with a pause of variable duration often associated with removing the cigarette from the mouth which was followed by inhalation of smoke (fig 6). By contrast on being directed only to mouth smoke, although a drag of smoke was taken from the cigarette, no inhalation of smoke took place (fig 6). Only three subjects were able to inhale smoke directly from the cigarette into the lungs to provide an assessment of direct smoke inhalation (fig 6). Subjects 10 and 11 failed to do so because of intolerance of the smoke, although both were able to perform "mouth" and normal smoking patterns.

\section{Volumes of "smoke" inhaled and change in nicotine}

There was little relationship between the volume of smoke inhaled, numbers of puffs of smoke and changes in venous blood nicotine (table 4). Both direct inhalation of smoke and normal smoking led to comparable volumes of smoke plus air being drawn into the lungs, suggesting that dilution of the smoke with air in both patterns of smoking was comparable. Where no smoke was

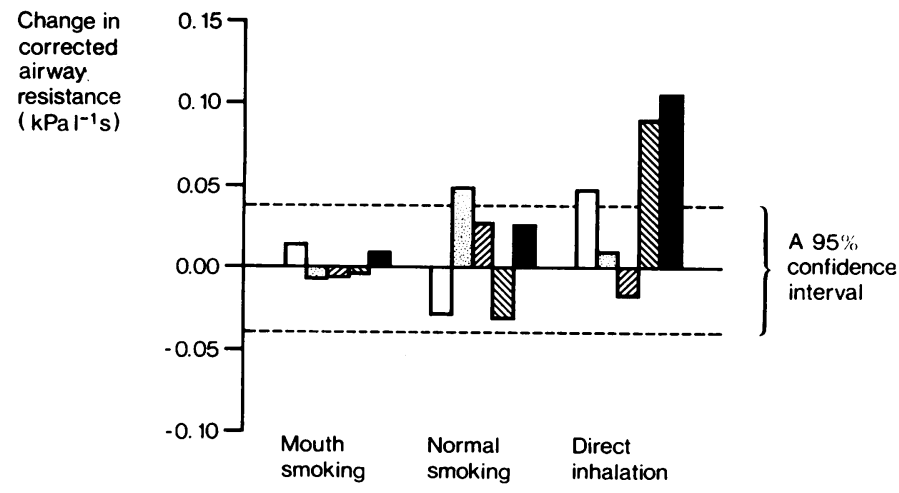

inhaled (mouth smoking and subject 10), no real change in nicotine level was observed (table 4).

\section{Airway resistance}

Subject 10 once again showed an increase in airway resistance after normal smoking and was the only subject to do so in this experiment. In subjects 9,12 , and 13 who failed to respond to normal smoking patterns, a direct inhalation of smoke from the cigarette caused marked increase in airway resistance (fig 7). The increase in airway resistance appeared related to the volume of smoke plus air that was inhaled but was not related to changes in venous blood nicotine levels.

\section{Discussion}

While allowing our subjects to smoke in their usual way, we set out to vary the amount of smoke each could potentially inhale by asking them to smoke in rapid succession increasing numbers of identical cigarettes. We also varied the $\operatorname{tar} /$ nicotine yield of smoke inhaled by asking them to smoke different types of cigarettes. The acute changes in airway function, caused by smoking, determined by either MEFVC analysis or airway resistance measurements were small
Fig 7 Change in covariance corrected airways resistance after each smoking pattern where each subject is represented by a separate column (subject $9, \square$ subject 10 圈, subject 11 , subject 12 $\mathbb{\$}$, subject $13 \square)$. The $95 \%$ confidence interval for any change considered significantly different from zero is shown. 
and appeared only to occur in certain individuals. Indeed, only three subjects $(1,6$, and 10$)$ consistently showed responses to smoking. No clear relationship could be found between the amount or type of smoke inhaled and size of the occasional acute airway response. Furthermore, the amount of smoke inhaled largely appeared independent of the number and type of cigarettes smoked. These observations suggest that smokers vary in the way they inhale cigarette smoke and that factors such as number and type of cigarette have only a minor influence upon their usual smoking response. Despite this, certain subjects appeared regularly to show evidence of acute narrowing after smoking which suggests an individual susceptibility.

The question as to how most habitual smokers avoid the irritant effects of cigarette smoke may be answered by our comparison of the effects of different patterns of smoking upon the acute airway response. It would appear that when a direct inhalation of smoke from the cigarette into the chest is achieved, there is consistent evidence of airway narrowing. A response was not consistently seen in either mouth or normal smoking and did not appear to be related to the volume of smoke inhaled when normal and direct smoking were contrasted. This suggests that the usual pattern of smoking, which we found to be similar to that observed by Rawbone et al ${ }^{15}$ and consisted of an initial "drag" of smoke into the mouth followed after a variable pause by a subsequent inhalation of smoke into the lungs, could minimise the irritant qualities of the tobacco smoke. The way of inhaling smoke, in particular the interval that smoke remains in the mouth, has an important role in determining the relative concentrations of the constituents reaching the lungs. ${ }^{16}$ Buccal absorption of water soluble compounds together with precipitation of particulate matter (tar) ${ }^{\mathbf{1 7}}$ leads to a relative increase of volatile insoluble compounds in the smoke entering the lungs during normal smoking. Direct inhalation of cigarette smoke prevents these adjustments occurring, enabling the full concentration of soluble gases such as sulphur dioxide and acrolein together with tar to reach the airways and so perhaps stimulate laryngeal and bronchial irritant receptors involved in the acute airway response. ${ }^{18}$ It is noteworthy in this respect that subject 10 who repeatedly responded to normal smoking was unable to inhale smoke directly and failed to directly draw any smoke into his chest, whereas smoking normally he was able to inhale smoke and tolerate the airway response to it.
The findings that smokers differ in their res sponse to smoking cigarettes and that in only $\bar{Q}$ proportion was acute airway narrowing observe despite varying the number and type of cigarette smoked, would appear at first sight discordan 8 with recent work showing responses in most suby jects. ${ }^{19-21}$ However, they are consistent with results of other studies where much larger numbers of smokers have been studied and wherद्E a similar degree of care has been taken to asses\$ the causes, other than smoking, of variation i the measurements of airway function. ${ }^{67}$ The् randomised and balanced nature of the design of our studies, in which each subject underwent ino random order each type of treatment (numbers of cigarettes smoked, type of cigarette smokes and type of smoking pattern) enabled the significance of interactions between those main factors influencing variation of measurements to be tested using analysis of variance. The result $\vec{\Phi}$ showed that some smokers consistently behave differently from the group findings.

Internal consistency of the results was als achieved in that the same intersubject variation? in response was seen with two different measure ments of airway function, MEFVC and airways resistance. Furthermore, the objectivity of these measurements was maintained as the observer were unaware of the type of treatment each sub ject underwent. The assessment of "dose" off smoke inhaled into the lungs by following changes in venous blood nicotine level in the studies using identical cigarettes is based on previous work by Russell ${ }^{22}$ and Haines. ${ }^{23}$ Our results confirm repor that mouth smoking - that is simply indrawing. smoke into the mouth without a subsequent im: halation-fails to alter blood nicotine levels. Th: occurs because acid smoke from flue-cures tobacco in English cigarettes prevents buccai absorption of nicotine. It was not possible to uso the same assessment when testing the smoking of different types of cigarette as they varied in the N nicotine yield. For this reason, changes in venous carboxyhaemoglobin were used to assess the amount of smoke inhaled, as carbon monoxide absorbed predominantly by the lungs and not buccal mucosa. ${ }^{16}$ This was based on the assump tion that co deliveries of different cigarettes werce roughly comparable, as co delivery depends on air permeability of the paper which affects bots smoke dilution and tobacco burning. The failure to show a relationship between the amount of smoke inhaled and airway response supports ouf notion that composition of the inhaled smoke is the most important determinant of airwa\& response rather than the amount or type of smoke 
inhaled. The similarity of the volumes of smoke inhaled during normal and direct smoke inhalation, which produced a markedly different response, also provides further support for this view.

We therefore conclude that there is a large intersubject variation in bronchial response to smoking which cannot be accounted for solely by the amount or type of smoke inhaled into the mouth.

Most habitual smokers appear able to adopt a pattern of smoking which avoids or minimises the irritant nature of cigarette smoke. Despite such manoeuvres, certain individuals still develop an acute airway response after smoking which may reflect an enhanced bronchial reactivity to cigarette smoke, and they may pursue a more rapid age-related decline in $\mathrm{FEV}_{1}$.

The pattern of smoke inhalation is important in determining the relative concentration of the constituents of cigarette smoke which reach the lungs. This is the first demonstration that the pattern of smoke inhalation is also important in the physiological response to smoking and certainly more important than the number of cigarettes smoked, or the tar content of the smoke. This observation raises the possibility that the pattern of smoking may also play a major contributory role in the development of bronchial disease associated with smoking. Future studies of the pathogenesis of smoke-related diseases should perhaps include some assessment of the manner of smoke inhalation.

We wish to thank the Research Department of the Imperial Group Bristol for their support and assistance with this study.

\section{References}

1 Russell MAH. Low tar medium nicotine cigarettes: a new approach to safer smoking. $\mathrm{Br}$ Med J 1976; 1:1430-3.

2 Nadel JA, Comroe JH. Acute effects of inhalation of cigarette smoke on airway conductance. J Appl Physiol 1961; 16:713-6.

3 Widdicombe JG. Physiological responses to inhalation of cigarette smoke and other irritant gases and aerosols. Bollettino della Societa Italiana di Biologia Sperimentale (Naples) 1973; 49:19-40.

4 Jeffrey P, Widdicombe JG. In: Aharonson EF, Ben-Davis A, Klingberg MA (eds.). Air pollution and the lung. New York: Wiley, 1976; 253-67.

5 Sterling GM. Mechanisms of bronchoconstriction caused by cigarette smoking. $\mathrm{Br}$ Med J 1967; 3:275-7.

6 Guyatt AR, Berry G, Alpers JH, Bramley AG,
Fletcher CM. Relationship of airway conductance and its immediate change on smoking to smoking habits and symptoms of chronic bronchitis. Rev Respir Dis 1970; 101:44-54.

7 McDermott M, Collins MM. Acute effects of smoking on lung airways resistance in normal and bronchitic subjects. Thorax 1965; 20:562-9.

8 Van der Lende R. Epidemiology of chronic nonspecific lung disease (chronic bronchitis). A critical analysis of three field surveys of CNSLD carried out in the Netherlands. Assen: Royal Van Gorcum, 1969.

9 Armitage P. Statistical methods in medical research. Oxford: Blackwell, 1971; 239.

10 Mead J. Peterson N, Grimby G, Mead J. Pulmonary ventilation measured from body surface movements. Science 1967; 156:1383-4.

11 Feyeraband C, Russell MAH. Improved gaschromatographic method and mico-extraction technique for the measurement of nicotine in biological fluids. J Pharm Pharmacol 1979; 31: 73-6.

12 Russell MAH, Wilson C, Patel UA, Cole PV, Feyeraband C. Comparison of effect on tobacco consumption and carbon monoxide absorption of changing to high and low nicotine cigarettes. $\mathrm{Br}$ Med J 1973; 4:512-6.

13 Higenbottam TW, Clark TJH. A method for standardising airway resistance for variations in lung volume. Clin Sci 1979; 57:397-400.

14 Kirk RE. Experimental design: procedures for the behavioural sciences. Belmont, California: Brook/Cole Publishing Company, 1968; 78.

15 Rawbone RG, Murphey K, Tate ME, Kone SJ. The analysis of smoking parameters, inhalation and absorption of tobacco smoke in studies of human smoking behaviour. In: Thornton RE (ed). Smoking behaviour. Edinburgh: Churchill Livingstone, 1978; 171.

16 Dalhamn T, Edfors ML, Rylander R. Retention of cigarette smoke components in human lung. Arch Environ Health 1968; 17:746-8.

17 Dalhamn T, Edfors ML, Rylander R. Mouth absorption of various compounds in cigarette smoke. Arch Environ Health 1968; 16:831-5.

18 Nadel JA, Widdicombe JG. Reflex effects of upper airway irritation on total lung resistance and blood pressure. J Appl Physiol 1962; 17: 861-5.

19 DaSilva AMT, Hamosh P. Effect of smoking a single cigarette on the "small airways." Appl Physiol 1973; 34:361-5.

20 McCarthy DS, Craig DB, Cherniack RM. The effect of acute, intensive cigarette smoking on maximal expiratory flow and the single-breath nitrogen washout trace. Am Rev Respir Dis 1976; 113:301-4.

21 Sobol BJ, Van Voorhies L, Emirgil C. Detection of acute effects of cigarette smoking on airway dynamics. Thorax 1977; 32:312-6. 
22 Russell MAH, Wilson C, Patel UA, Feyeraband C, Cole PV. Plasma nicotine levels after smoking cigarettes with high, medium, and low nicotine yields. Br Med J 1975; 2:414-6.
23 Haines CF, Damodar MS, Mahajan K, Miljkovic D, Miljkovic M, Vesell ES. Radioimmunoassa of plasma nicotine in habituated and nai smokers. Clin Pharmacol Ther 1975; 16:1083- 